\title{
EXPORTAÇÃO DE NUTRIENTES EM POVOAMENTOS DE Pinus taeda L. BASEADA EM VOLUME ESTIMADO PELO SISTEMA SISPINUS
}

\author{
Luiz Moro*, Carlos Alberto Ferreira**, Helton Damin da Silva***, \\ Carlos Bruno Reissmann**** \\ *Eng. Florestal, Dr., Valor Florestal - 1.moro@bol.com.br \\ **Eng. Agrônomo, Dr., Embrapa Florestas - calberto@cnpf.embrapa.br \\ ***Eng. Florestal, Dr., Embrapa Florestas - helton@cnpf.embrapa.br \\ ****Eng. Florestal, Dr., Departamento de Solos e Engenharia Agrícola, UFPR - reissman@ufpr.br \\ Recebido para publicação: 03/07/2006 - Aceito para publicação: 28/11/2007
}

\begin{abstract}
Resumo
Os plantios de Pinus ocorrem preferencialmente em regiões com menores preços de terras, localizados em áreas com solos de baixa fertilidade natural e conseqüentemente baixa produtividade. Essa condição, associada ao fato da não-fertilização dos plantios, via de regra, e à exportação de nutrientes nos desbastes e na colheita final, leva invariavelmente a perdas de produtividade futuras dos povoamentos. Nesse contexto, este trabalho teve como objetivo avaliar a aplicabilidade de modelos matemáticos, desenvolvidos em área florestais descritas por Moro (2005), ao SisPinus, para estimativa de nutrientes exportados na madeira, nas ocasiões da colheita da floresta. Para a realização deste estudo, foram selecionados plantios de P. taeda com 8, 12, 18 e 23 anos de idade, localizados em povoamentos comerciais, situados na região de Guarapuava (PR). Determinaram-se os nutrientes nos diversos segmentos do tronco, a cada metro, da base à altura comercial, no lenho e na casca. As equações desenvolvidas por Moro (2005) foram inseridas ao estimador de biomassa SisPinus, possibilitando a estimativa dos nutrientes exportados. O ajuste das equações desenvolvidas, dentro da variação de idade, qualidade do sítio, intensidade de manejo, entre outras variáveis, foi extremamente elevado, permitindo alta confiabilidade nas equações para estimativa de exportação dos nutrientes. Palavras-chave: Pinus taeda; exportação; nutrientes; Sispinus; modelos matemáticos.
\end{abstract}

\begin{abstract}
Nutrients export in Pinus taeda L. plantations based on estimated volume by using the SisPinus system. Pinus plantations in Brazil occur preferably in regions characterized as low cost lands, located over low fertility soils and, as a consequence, small wood productions. This condition, associated with the fact that fertilizing the plantation is not a routine practice, plus the effect of nutrients export during the thinning and the final harvest be considerable, leads to yield losses in the next plantations. In this context, this work was carried out to evaluate the applicability of mathematical models developed for forest plantations, as described by Moro (2005) to the Sispinus, in order to estimate the nutrients exported by the wood extraction. Commercial plantations of P. taeda at the ages of 8, 12, 18 , e 23 years were studied, all of them located in the region of Guarapuava (PR). The amount of nutrients both in wood as in the bark was determined in several disks taken at different positions of the trunk, one meter apart, since the basis up to the limit of the commercial height of the trunk. The mathematic equations developed by Moro (2005) were inserted into the biomass estimator Sispinus, allowing the estimates of the nutrients export. The adjustment of the equations, for the studied populations considering the different ages, site quality, management practices, among others, was extremely high, indicating a high level of confidence for the nutrient export estimate expressions. Keywords: Pinus taeda; exportation; nutrients; Sispinus; mathematical models.
\end{abstract}

\section{INTRODUÇÃO}

O setor florestal brasileiro teve seu grande impulso a partir das décadas de sessenta e setenta, mediante a promulgação da lei dos incentivos fiscais, que propiciou a expansão dos plantios com espécies dos gêneros Pinus sp. e Eucalyptus sp. 
A cultura do gênero Pinus teve como objetivo inicial abastecer o setor de papel e celulose. Entretanto, com a crescente demanda de madeira e a forte pressão pela preservação das florestas nativas, sua produção também se voltou para atender a demanda de madeira serrada e laminação.

Por essa e outras razões, tais como condições de mercado interno, ausência de exportação em escala significativa e até por questões de preconceito sobre o uso da madeira de Pinus sp., naquele período, a pesquisa e o desenvolvimento tecnológico não ostentaram os mesmos níveis de investimentos e resultados como aconteceu com as espécies do gênero Eucalyptus.

Diante dessa realidade, com a valorização recente da madeira de Pinus spp. e a crescente necessidade de expansão da área plantada para atender a demanda futura, algumas questões que estavam relegadas a segundo plano, tais como o manejo e o melhoramento genético e tecnológico, passaram a receber investimentos quase que espontaneamente, com o intuito de aumentar o potencial produtivo e a sustentabilidade das florestas. As técnicas de manejo, como espaçamentos, idade de desbastes, fertilizações e melhoramento genético, são questões indispensáveis e que podem contribuir de forma decisiva na demanda futura do mercado.

\section{REVISÃO BIBLIOGRÁFICA}

Nos estados do sul do Brasil, concentram-se os maiores plantios do gênero Pinus (SBS, 1998), sendo $P$. taeda e $P$. elliottii as principais espécies cultivadas.

As extensas áreas plantadas evidentemente ocorreram numa variação muito grande de classes de solos e clima, como descritos por Reissmann; Wisniewski (2000). Como conseqüência, observa-se acentuada diferença de produtividade em função do tipo de solo em que está estabelecido o plantio, como relatado por Carvalho et al. (1999), entre outros autores.

Essa condição, associada ao fato da não-fertilização dos plantios de Pinus spp., de modo geral, e à exportação de nutrientes do sítio pela retirada da madeira (lenho e casca), nos desbastes e colheita final, leva invariavelmente à perda de produtividade futura dos sítios florestais e conseqüentemente das florestas plantadas. Essas espécies são preferidas pelo setor florestal e industrial brasileiro por apresentarem bom crescimento, baixa exigência nutricional (PRITCHETT; ZWINDORF, 1961) e boas características físicas e tecnológicas, que atendem plenamente as exigências industriais na produção de madeira para serraria, celulose e papel, aglomerados, laminados e outros derivados. A rapidez de crescimento e a ausência de sintomas de deficiências, via de regra, particularmente nas primeiras rotações, condicionam a idéia de que as plantações de Pinus spp. dispensariam a prática da fertilização mineral. Diversos estudos têm demonstrado aumento na produtividade em resposta à elevação do nível de fertilidade do solo. Vogel (2003) verificou que houve resposta positiva para o fósforo e o potássio, demonstrando a importância desses macronutrientes no crescimento inicial de $P$. taeda. Em condições de solos arenosos e de baixa fertilidade, Silva et al. (2003) verificaram que Pinus taeda apresentou resposta positiva à aplicação de potássio, magnésio e boro.

A influência das técnicas silviculturais na qualidade da madeira foi estudada por muitos pesquisadores, tais como Fielding (1967), Nicholls (1971), Cown (1974b), Rudman e Mckinnell (1975) e Ohta (1981), entre outros. Entre os fatores estudados estão a poda, o desbaste, a fertilização, a irrigação e o espaçamento. A partir da década de 60 , já havia preocupações conseqüentes da adoção de rotações curtas e sucessivas, além de possíveis distúrbios dos sítios submetidos às explorações constantes e alterações que comprometessem a manutenção da produtividade, principalmente nas áreas marginais, que concentram a maioria dos solos de baixa fertilidade (SILVA, 1996).

Um dos problemas da grande maioria das empresas florestais é a falta de informações precisas sobre o potencial do solo para produzir madeira. Essas informações são de elevada importância para a execução de um plano de manejo, o qual é essencial ao bom desenvolvimento de qualquer empreendimento florestal (RIGATTO, 2002).

Os fatores físicos, químicos e biológicos do solo e as relações com o estado nutricional e a produtividade das espécies, demonstram estreita interdependência entre essas variáveis. Ademais, os maciços florestais, via de regra, são estabelecidos sob condições de solos marginais e de baixa fertilidade natural, sendo facilmente visível, nessas condições, o grande acúmulo da serapilheira sobre o solo, sinais claros de decomposição lenta, que por sua vez reduz a liberação de nutrientes às plantas. 
Laso Garicoits (1990) e Reissmann; Zöttl (1987) constataram que o crescimento de P. taeda foi fortemente afetado por limitações de disponibilidades na oferta de $\mathrm{P}, \mathrm{K}, \mathrm{Mg}$ e $\mathrm{Zn}$, destacando como mais limitantes K e Zn, o que, em parte, está de acordo com Reissmann ${ }^{1}$ (1981), citado por Reissmann; Wisniewski (2000), que em situações de extrema pobreza de nutrientes no solo o elemento $\mathrm{N}$ apresentou restrições à nutrição e ao crescimento de Pinus elliottii.

Um conjunto de experimentos de adubação em Pinus elliottii e Pinus taeda, conduzidos em diversas empresas do IPEF, foi analisado por Balloni, Jacob e Simões (1978). Concluíram que havia respostas positivas para a adubação fosfatada, mas ausência de resposta aos outros nutrientes.

Teores foliares baixos de $\mathrm{Mg}$ e $\mathrm{Zn}$ foram associados com baixo crescimento em altura de Pinus elliottii na região de Telêmaco Borba (PR) e considerados como limitantes ao crescimento dessa espécie por Menegol (1991). Os teores foliares de $\mathrm{N}, \mathrm{Mg}, \mathrm{Cu}, \mathrm{K}$ e $\mathrm{Zn}$ foram os mais correlacionados com a altura dominante aos 15 anos de idade.

O manejo químico, práticas de reposição dos nutrientes, conforme a necessidade da cultura, em plantações de Pinus sp requer estudo detalhado, sobretudo, levando-se em consideração o aspecto da fertilidade natural do solo, a capacidade deste de atender em quantidade e qualidade a demanda dos nutrientes pela planta, a necessidade e os níveis críticos da espécie, a época, a formulação e a forma de aplicação dos nutrientes.

A simples possibilidade de uma fertilização ser efetuada em um período inadequado, como, por exemplo, no período de inverno, quando a atividade metabólica da planta é baixa, ou num período em que o solo se encontre em condições de umidade abaixo daquela que permita o fluxo normal dos solutos do solo, pode condenar ao insucesso a prática da fertilização mineral.

Ao se elaborar um programa de manejo químico para uma população florestal, é importante não apenas o estudo dos nutrientes individualizados, mas primordial levar em consideração a relação entre os nutrientes. Reissmann e Wisniewski (2000) discutem as relações entre os teores de N/K e P/Zn nas acículas de Pinus taeda, e sua relação com a produtividade da espécie. A importância de cada nutriente e sua ação bioquímica também são abordadas pelos referidos autores.

Dentre os levantamentos de solo e de estados nutricionais e sua relação com a produtividade, destacam-se os trabalhos relatados por Reissmann, Koehler e Paula Souza (1990), conduzidos na região de Ponta Grossa e Telêmaco Borba (PR), para Pinus taeda. Os autores destacam que essa espécie se apresenta mais sensível às propriedades do solo e mais exigente em nutrientes, quando comparada $P$. elliottii, chamando a atenção às concentrações extremamente baixas de $\mathrm{K}, \mathrm{Mg}$ e $\mathrm{Zn}$ nos sítios menos produtivos.

As discussões dos resultados experimentais publicados no Brasil demonstraram que para Pinus spp., de forma geral, respondem menos à adubação que em Eucalyptus spp. Melhores resultados com espécies do gênero Pinus foram obtidos com a aplicação de $\mathrm{P}, \mathrm{K}$ e de Ca mais $\mathrm{Mg}$ na forma de calcário. Por vezes, a aplicação de $\mathrm{N}$ tem se mostrado prejudicial ao desenvolvimento das árvores (HAAG, 1983).

A redução de produtividade em rotações sucessivas não tem sido comumente relatada. Possivelmente, no curto prazo, a troca do material cultivado por genótipos mais eficientes na extração e aproveitamento de nutrientes, e melhores cuidados de implantação e manutenção dos povoamentos tenha encoberto as perdas de produtividade pela redução da oferta de alguns nutrientes. No entanto, torna-se claro que, a médio e longo prazo, a manutenção da produtividade de povoamentos florestais dependerá da reposição, no sítio, dos nutrientes contidos na madeira e exportados no processo de exploração florestal (FERREIRA et al., 2001).

A ciclagem biológica de nutrientes é um processo importante na nutrição de Pinus spp., sobretudo nos sítios mais pobres. Portanto, os fluxos de entrada e de saída e o armazenamento de nutrientes na serapilheira acumulada devem ser estudados e levados em consideração nas decisões de manejo.

O conhecimento da ciclagem de nutrientes é extremamente importante para se avaliar o impacto e as implicações das ações de manejo na disponibilidade de nutrientes no solo e na produtividade futura dos povoamentos florestais. A preocupação com a exaustão de nutrientes dos sítios florestais já existia no século XIX, quando silvicultores alemães recomendavam que a reposição dos nutrientes extraídos pela

\footnotetext{
${ }^{1}$ Reissmann, C. B. Nährelementversorgung und Wuchsleistung von Kiefernbeständen in Süd Brasilien. Friburg i. Br. Alemanha, 1981, 169 p. (Tese de Doutorado).
} 
madeira e outros produtos florestais deveria ser no mínimo igual às retiradas, caso contrário, a produtividade seria prejudicada (FERREIRA et al., 2001).

Segundo Castro ${ }^{2}$ et al., citados por Valeri (1988), povoamentos de P. oocarpa aos 18 anos de idade produziram cerca de 172 megagrama $(\mathrm{Mg}) /$ ha de peso de matéria seca total da parte aérea das árvores, sendo que a distribuição desse peso foi de $14 \%$ na copa, $13 \%$ na casca e $73 \%$ na madeira do fuste. A distribuição dos nutrientes N, P, Ca, Mg, Fe, Mn e Zn foi em média de 37\% na copa, 15\% na casca e $48 \%$ na madeira do fuste, em relação ao peso total.

Segundo Silva (1996), o manejo intensivo das florestas plantadas pode aumentar significativamente a produção de biomassa, entretanto, aumenta-se também a remoção dos nutrientes do sítio. O acúmulo de nutrientes nos diferentes compartimentos das árvores, em geral, é maior na madeira que nas folhas e ramos, apesar das concentrações serem maiores nas folhas, casca, ramos, lenho e raízes (CASTRO, 1984). As concentrações de nutrientes geralmente mudam com a idade das árvores, com a espécie, com a qualidade do solo, com a época de coleta e com a idade fisiológica das amostras (PRITCHETT, 1979; POGGIANI; COUTO; SUITER FILHO, 1983).

Trabalhos envolvendo a exportação de nutrientes, fluxos da ciclagem biológica de nutrientes, morfologia e química da serapilheira acumulada sobre o solo foram desenvolvidos por Valeri (1988), Koehler (1989) e Trevisan (1992).

O hábito comum entre a maioria das empresas florestais de se explorar o tronco das árvores (lenho e casca) e, em casos mais extremos, o aproveitamento de ramos juntamente com as folhas e resíduos da colheita, para a produção de energia, requer que sejam quantificados os nutrientes nos diferentes componentes exportados, os quais serão imprescindíveis ao crescimento das populações futuras.

Alternativa adotada e que pode pelo menos em parte compensar essas perdas é a reposição dos nutrientes através do retorno da cinza proveniente da queima dos resíduos florestais e de outros componentes das árvores (MORO; GONÇALVES, 1995; GONÇALVES; MORO, 1995).

A não-reposição dos nutrientes exportados associada às perdas por processos erosivos e de lixiviação conduzirá, invariavelmente, a uma aceleração no depauperamento dos níveis de fertilidade química do solo, afetando diretamente a produtividade dos sítios florestais.

Mälkönem (1976), estudando exploração de coníferas de diferentes espécies, concluiu que a retirada tradicional da madeira não empobrece o solo, uma vez que o teor de nutrientes da madeira é muito baixo, entretanto, sugere que os resíduos dos desbastes permaneçam no talhão, com a função de manter os nutrientes contidos nesse material.

A quantidade de nutrientes exportados com a madeira retirada depende da idade das árvores. No início da formação do cerne, parte dos nutrientes móveis, como N, P e K, são translocados para outras partes da árvore, através da ciclagem interna dos nutrientes, enquanto que o $\mathrm{Ca}$ acumula-se no caule. Dependendo das condições do sítio, alguns desses nutrientes podem ser limitantes para o crescimento das árvores nas rotações futuras.

Valeri (1988) considera que, com a retirada da madeira, uma quantidade considerável de nutrientes é exportada do sistema, e sua reposição é tão mais importante quanto mais limitante nutricionalmente for o sítio.

Um outro fator a ser considerado é a manutenção da produtividade dos sítios, principalmente em condições de baixo suprimento de elementos essenciais às árvores pelo solo. As explorações intensivas em rotações curtas, sem previsão de um período mínimo necessário para reposição de nutrientes, têm sido apontadas como as maiores responsáveis pela exaustão do solo (FERREIRA et al., 2001). Os autores ainda concluem pela inconveniência da exploração total da árvore e da importância da manutenção das galhadas e acículas no campo. Quando possível, recomenda-se o descascamento das toras no local de exploração, ou mesmo o retorno ao solo da casca e/ou da cinza proveniente de sua queima, devido à quantidade relativamente alta de nutrientes presentes nesses materiais.

Segundo Wells e Jorgensen (1979), a exploração convencional do fuste comercial exporta uma quantidade de nutrientes equivalente à que é introduzida no sistema anualmente, através da atmosfera, em povoamentos de rotação acima de 35 anos.

\footnotetext{
${ }^{2}$ Castro, C. F. de; Poggiani, F.; Nicolielo, N. Distribuição da fitomassa e nutrientes em talhões de Pinus oocarpa com diferentes idades. IPEF, 20: 61-74, 1980.
} 
Timoni;Pagano (1986) verificaram em desbastes de P. kesiya com 16 anos de idade que, quando foram removidos o tronco e a casca mais a madeira, o nutriente mais exportado foi o $\mathrm{P}$, em seguida o $\mathrm{S}>$ $\mathrm{Mg}>\mathrm{Ca}>\mathrm{K}>\mathrm{N}$. Para os micronutrientes, a ordem decrescente foi o $\mathrm{Zn}>\mathrm{Na}>\mathrm{B}>\mathrm{Mn}>\mathrm{Fe}$.

Segundo Smith (1962), as folhas não são as únicas partes da planta capazes de representar o estado nutricional das árvores, entretanto, são recomendadas e utilizadas no monitoramento nutricional para a maioria dos elementos, principalmente aqueles que afetam diretamente a fotossíntese. As concentrações de nutrientes de outras partes da árvore, tais como o tronco, a casca e os galhos, têm sido utilizadas para os cálculos de exportações e estudo de eficiência de utilização dos nutrientes nas espécies florestais.

Com o objetivo de se prognosticar o crescimento de florestas de $P$. elliottii e $P$. taeda, foi desenvolvido um software na Universidade Estadual da Carolina do Norte (NCSU), EUA, e posteriormente adaptado pelo seu autor, Dr. Willian L. Hafley, e pela equipe do Centro Nacional de Pesquisa de Florestas (CNPF/EMBRAPA), para plantios de Pinus spp. estabelecidos no Sul do Brasil (OLIVEIRA; OLIVEIRA; HAFLEY, 1991).

A versão brasileira desse software passou a ser denominada SisPinus, que possibilita, através de avaliações de medições de determinadas variáveis, em povoamentos ainda jovens, predizer o crescimento em idades futuras, sendo, portanto, uma ferramenta de grande utilidade para técnicos florestais que atuam na área de manejo florestal nas tomadas de decisão das operações de desbastes.

O sistema SisPinus vem sendo utilizado em grande escala desde 1989 por diversas empresas que possuem plantios de P. elliottii e P. taeda, no Sul do Brasil e países do Mercosul.

Segundo Oliveira e Oliveira (1991), o SisPinus pode ser operado em microcomputadores padrão IBM/PC com configuração mínima. Os imputs necessários são o número de árvores plantadas por hectare, a porcentagem de sobrevivência um ano após o plantio, os tipos de desbastes previstos ou adotados (seletivo, sistemático ou misto), as idades dos desbastes (ocorridos ou a serem simulados), o índice de sítio, a equação de volume (e unidades associadas) e as idades selecionadas para os relatórios.

Para estimativa das características de desenvolvimento do povoamento, o software utiliza-se da distribuição diamétrica de Johnson, mais conhecida como $\mathrm{S}_{\mathrm{B}}$ (univariada, que descreve a distribuição marginal de diâmetro e altura) ou $\mathrm{S}_{\mathrm{BB}}$, (bivariada, que descreve a distribuição marginal conjunta de diâmetro e altura). O sistema apresenta como relatório de saída uma tabela de produção para as idades desejadas, considerando-se as atividades de manejo estipuladas pelo usuário, como, por exemplo, desbaste sistemático aos 8 anos de idade, desbastes seletivos aos 12 e 18 anos e corte final aos 23 anos. Apresenta ainda tabelas de freqüência do número de árvores por hectare por classe de diâmetro para as idades em que foi simulado um desbaste, e para a idade de corte final.

O sistema SisPinus tem sido utilizado também na estimativa de perdas na produção de madeira provocadas por ataques de Sirex noctilio, para o planejamento da produção de povoamentos de Pinus elliottii e $P$. taeda atacados. Diferentes níveis de ataques foram simulados e as perdas ocorridas na produção de madeira foram quantificadas, em termos de volume e em valores econômicos (OLIVEIRA et al., 1992).

Diante da necessidade de se garantir a viabilidade do negócio florestal através do abastecimento dos parques industriais estabelecidos, atender a demanda crescente e promover a sustentabilidade dos sítios florestais, para usufruto das gerações futuras, estudos que abordem questões relacionadas à exportação de biomassa e nutrientes são assuntos que merecem destaque. Nesse sentido, os objetivos deste trabalho foram:

a) quantificar os valores de exportação de biomassa e nutrientes, nas ocasiões de intervenções de colheita florestal em desbastes ou corte final do povoamento de Pinus spp.;

b) avaliar a aplicabilidade de modelos matemáticos do SisPinus como estimador de nutrientes exportados na colheita da madeira em diferentes estágios e condições de manejo em que se encontre o povoamento florestal.

\section{MATERIAL E MÉTODOS}

$\mathrm{O}$ estudo foi realizado em áreas comerciais pertencentes às empresas Manasa (Madeireira Nacional S.A.) e Santa Maria Papel e Celulose, nos municípios de Guarapuava, Campina do Simão e Canta Galo, no estado do Paraná, com localização aproximada de latitude S $25^{\circ} 10^{\prime} 40^{\prime \prime}$ a $25^{\circ} 24^{\prime 2} 28^{\prime \prime}$, 
longitude W $51^{\circ} 11^{\prime} 43^{\prime \prime}$ a $52^{\circ} 14^{\prime} 42^{\prime \prime}$ e altitude de $905 \mathrm{~m}$ a $1075 \mathrm{~m}$, conforme descritos por Moro (2005). O clima da região de influência das empresas Manasa (Madeireira Nacional S.A.) e Santa Maria Papel e Celulose é classificado, segundo Köppen, como sendo $\mathrm{Cfb}$, com verões frescos de temperatura média do mês mais quente inferior a $22{ }^{\circ} \mathrm{C}$ e do mês mais frio igual a $12{ }^{\circ} \mathrm{C}$, sendo durante onze meses maior que $10{ }^{\circ} \mathrm{C}$, com até cinco geadas por ano. A temperatura média anual é de $16,7{ }^{\circ} \mathrm{C}$. A precipitação pluviométrica distribui-se regularmente durante o ano, variando entre 101,6 a $187,5 \mathrm{~mm}$ por mês, com média anual de 1.674,8 mm (SIMEPAR) ${ }^{3}$.

Segundo a Carta de Levantamento de Reconhecimento dos Solos do Estado do Paraná (EMBRAPA, 1984), ocorrem na região de Guarapuava, predominantemente, os seguintes solos: Latossolo Bruno Álico e Associação de Latossolo Bruno Álico e Cambissolo Álico. Em menores quantidades, os solos Cambissolo Húmico Gleico, Glei pouco Húmico, Solos Orgânicos e Solos Litólicos. Os solos predominantes das áreas de estudo são das classes de Latossolos Brunos e Cambissolos.

Os materiais foram coletados em povoamentos com 8, 12, 18 e 23 anos de idade. Coletaram-se amostras de 2 árvores para cada estrato (dominante, co-dominante e dominado), totalizando 24 árvores, representados por discos do tronco contendo lenho e casca.

A densidade básica pelo método do máximo teor de umidade e o volume arbóreo foram calculados pelas seguintes expressões:

$$
\mathrm{db}=1 /[((\mathrm{Pm}-\mathrm{Pas}) / \mathrm{Pas})+(1 / \mathrm{Gs})]
$$

Em que:

$\mathrm{db}$ : densidade básica $\left(\mathrm{g} / \mathrm{cm}^{3}\right)$;

Pm: peso saturado após a remoção, com papel absorvente, da água superficial;

Pas: peso absolutamente seco, conseguido através da secagem em estufa a $105 \pm 3{ }^{\circ} \mathrm{C}$, até peso constante; Gs: densidade da substância madeira, admitindo-se $1,53 \mathrm{~g} / \mathrm{cm}^{3}$ como média.

$$
V=1 / 2 \times\left(\pi D^{2} / 4+\pi d^{2} / 4\right) \times h
$$

Em que:

$\mathrm{V}$ : volume do segmento $\left(\mathrm{m}^{3}\right)$;

D: diâmetro maior do segmento $(\mathrm{m})$;

d: diâmetro menor do segmento $(\mathrm{m})$;

$\mathrm{h}$ : comprimento do segmento (m).

O volume das árvores foi obtido empregando-se a equação de Smallian, que considera o somatório dos volumes de cada torete. A obtenção do volume dos toretes foi através da média do somatório do diâmetro maior com o diâmetro menor multiplicado pelo comprimento de cada seção (o fator de multiplicação foi igual a um para os toretes com comprimento de um metro, 0,3 para o segmento imediatamente inferior ao DAP, 0,7 para o segmento imediatamente superior ao DAP e fator variável conforme o tamanho medido no último segmento da árvore).

Após a obtenção do volume total (lenho e casca), obteve-se o volume sem casca (lenho). Pela subtração do volume do lenho do volume total, obteve-se o volume da casca e, com os valores de densidade e volume por segmento calculou-se o peso por segmento e o peso total para ambos os componentes.

$$
\mathrm{P}=\mathrm{db} \times \mathrm{V}
$$

Em que:

P: peso $(\mathrm{kg})$;

$\mathrm{db}$ : densidade básica $\left(\mathrm{kg} / \mathrm{m}^{3}\right)$;

$\mathrm{V}$ : volume do segmento $\left(\mathrm{m}^{3}\right)$.

\footnotetext{
${ }^{3}$ Informação recebida por e-mail da engenheira Fabiana Maia (2005), ex-funcionária da Manasa.
} 
Através da obtenção dos dados do volume, do conteúdo de nutrientes e as equações para estimativa de exportação de nutrientes, desenvolvidas por Moro (2005), procedeu-se a seleção de novos modelos matemáticos, que foram adaptados ao estimador SisPinus para a estimativa da exportação de nutrientes nos desbastes e no corte final do povoamento. As análises foram executadas através da utilização do sistema SAS, licenciado para Embrapa (Empresa Brasileira de Pesquisa Agropecuária). A seleção dos modelos foi através da análise dos coeficientes de determinação $\left(\mathrm{R}^{2}\right)$, do erro de estimativa do modelo e da distribuição gráfica dos resíduos. Para a análise dos dados, foi necessária a utilização de análise multivariada, que, segundo Johnson; Wiechern (1998), apresenta três objetivos principais: excluir as variações devidas a erros não encontrados, sumarizar os dados e revelar a estrutura dos mesmos. Os modelos matemáticos selecionados foram submetidos à análise gráfica para os valores preditos dos nutrientes e à distribuição da normalidade dos resíduos pelo teste de Shapiro-Wilks (ROYSTON, 1992).

\section{RESULTADOS E DISCUSSÃO}

Para o cálculo da exportação de nutrientes através do uso do SisPinus, foi necessário relacionar o conteúdo de nutrientes na árvore com os respectivos diâmetros. Assim, foram ajustadas equações polinomiais de segundo grau e exponenciais. Com exceção do nitrogênio, que apresentou uma ligeira superioridade nas menores e maiores classes de diâmetros mediante a utilização da equação polinomial, para todos os demais nutrientes, os modelos exponenciais foram mais precisos.

$\mathrm{Na}$ tabela 1 são apresentadas as equações desenvolvidas para a estimativa de nutrientes exportados, através da inserção dessas equações no sistema SisPinus.

Tabela 1. Equações para estimativa de exportação de nutrientes no lenho de $P$. taeda, para conexão ao sistema SisPinus.

Table 1. Equations to estimate nutrients exportation in P. taeda wood, to connect to SisPinus system.

\begin{tabular}{lccc}
\hline Nutrientes & \multicolumn{1}{c}{ Equações } & $\mathbf{R}^{\mathbf{2}}$ & $\mathbf{P r}>\mathbf{F}$ \\
\hline Nitrogênio & $\mathrm{N}=0,2442 \times \mathrm{DAP}^{2,1259}$ & 0,99 & 0,0001 \\
Fósforo & $\mathrm{P}=0,1085 \times \mathrm{DAP}^{1,6373}$ & 0,96 & 0,0080 \\
Potássio & $\mathrm{K}=0,0333 \times \mathrm{DAP}^{2,3649}$ & 0,98 & 0,0020 \\
Cálcio & $\mathrm{Ca}=0,0068 \times \mathrm{DAP}^{2,9573}$ & 0,99 & 0,0015 \\
Magnésio & $\mathrm{Mg}=0,0015 \times \mathrm{DAP}^{3,0517}$ & 0,99 & 0,0011 \\
\hline
\end{tabular}

Devido à pouca superioridade na precisão na estimativa do nitrogênio com a equação polinomial e para padronização das equações, optou-se por utilizar, para todos os nutrientes, as equações exponenciais.

As equações para estimativa dos nutrientes apresentaram coeficientes de determinação igual ou superior a 0,96 , o que garante uma boa estimativa para os conteúdos dos nutrientes exportados.

O diâmetro é a variável dendrométrica mais utilizada também para estimativas de biomassa e volume em povoamentos florestais. Silva (1996) encontrou equações similares para a estimativa da biomassa e do volume de madeira de E. grandis, aos sete anos de idade. Obteve volume de tronco = $0,000952 \times \mathrm{DAP}^{2}$; volume de alburno $=0,000472 \times \mathrm{DAP}^{2}$; Peso: de casca $=37,7823 \times \mathrm{DAP}$; alburno $=$ $235,9570 \times \mathrm{DAP}^{2} ;$ cerne $=\mathrm{P}$ total $-(\mathrm{P}$ alburno $+\mathrm{P}$ casca $)$; tronco $=442,6520 \times \mathrm{DAP}^{2} ;$ galhos $=28,4492 \times$ $\mathrm{DAP}^{2}-107,2099 \times$ HT e folhas $=35,0359 \times \mathrm{DAP}^{2}-134,8311 \times$ HT.

Para se avaliar as quantidades de nutrientes nos diferentes componentes das árvores, o processo mais utilizado e preciso tem sido o de abate das árvores, com determinação da biomassa seca e determinação dos teores de nutrientes em cada compartimento. Dentro dessa linha de trabalho, o autor Alemag (1980) recomenda abater no mínimo quatro árvores por classe de diâmetro, com intervalo de 5 $\mathrm{cm}$, para proporcionar equações estimadoras do peso de matéria seca em cada componente. A variável DAP é a mais simples e empregada com bastante precisão, como no caso da utilização pelos autores Castro et al. (1980), Pinheiro (1980) e Van Lear et al. (1984), que obtiveram resultados satisfatórios. Em estudos desenvolvidos por Singh (1982), para estimar o peso de matéria seca dos componentes aéreos de diversas espécies no Canadá, foram revelados valores de $\mathrm{R}^{2}$ variando de 0,96 a 0,99 . 
De posse dos modelos selecionados e procedendo-se sua inserção no estimador de biomassa do SisPinus, torna-se possível a obtenção da estimativa dos nutrientes exportados durante as intervenções de desbastes e colheita final da floresta. A título de exemplificação, para estimativa de exportação de nutrientes, fez-se uso das equações apresentadas na tabela 1 , em situação simulada de um povoamento com índice de sítio de $21 \mathrm{~m}$ e desbastes previstos para 8, 12 e 16 anos, com corte final aos 20 anos de idade. O planejamento para o exemplo previu a retirada de 577 árvores no primeiro desbaste e 291 no segundo e terceiro desbastes. Os resultados dessa simulação estão apresentados na tabela 2.

Observa-se, na tabela 2, a exportação dos nutrientes, obtida através da utilização das equações desenvolvidas e inseridas no SisPinus.

Tabela 2. Simulação de exportação de nutrientes pelo lenho $(\mathrm{kg} / \mathrm{ha})$ com utilização das equações desenvolvidas e de posse do simulador SisPinus para $P$. taeda, em função da idade de desbaste $(8,12,16$ anos e corte final aos 20 anos).

Table 2. Nutrients exportation simulation through the wood $(\mathrm{kg} / \mathrm{ha})$ with the use of development equations in SisPinus simulator for Pinus taeda, considering thinning age (8, 12, 16 and final harvest at 20 years).

\begin{tabular}{lcccccc}
\hline $\begin{array}{l}\text { Idade } \\
\text { (anos) }\end{array}$ & Situação & N & P & K & Ca & Mg \\
\hline 8 & Total & 148,4 & 16,8 & 39,5 & 42,4 & 12,2 \\
& Remanescente & 94,1 & 10,6 & 25,1 & 26,9 & 7,7 \\
& Removido & 54,3 & 6,2 & 14,4 & 15,5 & 4,5 \\
12 & Total & 163,9 & 16,3 & 46,5 & 58,4 & 17,2 \\
& Remanescente & 129,3 & 12,5 & 37,2 & 48,1 & 14,2 \\
& Removido & 34,6 & 3,8 & 9,3 & 10,3 & 3,0 \\
16 & Total & 184,0 & 16,4 & 55,1 & 79,0 & 23,8 \\
& Remanescente & 119,1 & 10,3 & 36,1 & 53,4 & 16,1 \\
& Removido & 64,9 & 6,1 & 19,0 & 25,6 & 7,7 \\
20 & Total & 140,0 & 11,7 & 43,2 & 67,0 & 24,0 \\
& Remanescente & 0 & 0 & 0 & 0 & 0 \\
& Removido & 140,0 & 11,7 & 43,2 & 67,0 & 24,0 \\
Total & Removido & 293,8 & 27,8 & 85,9 & 118,4 & 39,2 \\
\hline
\end{tabular}

A exportação de nutrientes para a idade de 8 anos é cerca de $50 \%$ maior que para a idade de 12 anos. Isso se explica devido à maior quantidade de árvores que são desbastadas naquela idade, 577 árvores retiradas no primeiro desbaste, contra 291 no segundo e terceiro desbastes.

Outra explicação para essa constatação é, provavelmente, a maior presença de tecidos jovens, com maior concentração de nutrientes, bem como o fato de se tratar de primeiro desbaste, quando o diâmetro das árvores é menor, proporcionando uma maior percentagem de casca, com maior concentração de nutrientes em relação ao lenho, comparando-se aos desbastes subseqüentes.

A maior exportação de nutrientes aos 16 anos em relação aos 12 anos deve-se também ao maior volume de biomassa acumulado e, conseqüentemente, ao maior acréscimo do conteúdo de nutrientes nas árvores.

Em termos de nutrientes exportados, foi observada a seguinte ordem decrescente: nitrogênio, cálcio, potássio, magnésio e fósforo. Essa ordem está de acordo com a encontrada por Valeri (1988).

A quantidade total acumulada na madeira dos três desbastes, por exemplo, de $\mathrm{K}$, corresponde a uma exportação de aproximadamente $31 \%$ da quantidade do elemento presente na biomassa do povoamento, incluindo a manta orgânica. Situação semelhante é verificada também para o $\mathrm{Ca}, \mathrm{Mg}, \mathrm{Zn}$ e B. A falta de reposição desses nutrientes pode levar à redução da produtividade dos povoamentos em médio prazo (FERREIRA et al., 2001).

$\mathrm{Na}$ tabela 3 são apresentadas as equações desenvolvidas para a estimativa de exportação de nutrientes da casca, constando o diâmetro como a única variável independente. Os valores dos coeficientes de correlação foram extremamente elevados, praticamente muito próximos de 1. O modelo que estima o fósforo apresentou o menor valor $(0,98)$, que também confere alta confiabilidade na 
estimativa, indicando alta correlação entre as variáveis associadas. Para todos os modelos, o valor de F da análise de variância foi significativo em nível de $1 \%$.

Tabela 3. Equações para estimativa de exportação de nutrientes na casca de $P$. taeda, para conexão ao sistema SisPinus.

Table 3. Equations to estimate nutrients exportation in the bark of Pinus taeda, to SisPinus system connection.

\begin{tabular}{lccc}
\hline Nutrientes & \multicolumn{1}{c}{ Equações } & $\mathbf{R}^{\mathbf{2}}$ & Pr>F \\
\hline Nitrogênio & $\mathrm{N}=0,0004 \times \mathrm{DAP}^{3,6098}$ & 0,99 & 0,0006 \\
Fósforo & $\mathrm{P}=0,0001 \times \mathrm{DAP}^{3,3516}$ & 0,98 & 0,0021 \\
Potássio & $\mathrm{K}=0,0760 \times \mathrm{DAP}^{1,6148}$ & 0,99 & 0,0003 \\
Cálcio & $\mathrm{Ca}=0,0001 \times \mathrm{DAP}^{3,9058}$ & 0,99 & 0,0001 \\
Magnésio & $\mathrm{Mg}=0,0001 \times \mathrm{DAP}^{3,5435}$ & 0,99 & 0,0005 \\
\hline
\end{tabular}

Silva (1996), ao estudar diversos modelos para diversas idades na avaliação de conteúdo de macronutrientes na casca de Eucalyptus grandis, obteve as melhores estimativas, com exceção apenas para o fósforo aos três anos de idade, com amostragem da casca nos seguintes segmentos de altura do tronco: nitrogênio e magnésio em 1,0-1,3 m; fósforo em 1,3-2,0 m; potássio e cálcio em 1,3-2,0 m. Desse modo, fica evidenciado que o DAP ou posição da árvore próxima a esse ponto é uma localização precisa para estimativa dos nutrientes no componente casca.

Para visualização de estimativa de exportação de nutrientes na casca de P. taeda (Tabela 4), foram utilizadas as equações apresentadas na tabela 3, acopladas ao sistema SisPinus. Como exemplo ilustrativo, considerou-se um povoamento com três desbastes $(8,12$ e 16 anos), com remoção de 577 árvores no primeiro desbaste e 291 para os demais, com corte final aos 20 anos.

A ordem de exportação dos nutrientes através da casca em $P$. taeda foi mais expressiva para nitrogênio, cálcio, potássio, magnésio e fósforo, mantendo praticamente a mesma ordem encontrada para o lenho, estando de acordo com citação de Gonçalves (1995), em que a quantidade de nutrientes em componentes exportados, de modo geral, é muito maior para as espécies de Eucalyptus relativamente às de Pinus, principalmente para os nutrientes $\mathrm{K}, \mathrm{Ca}$ e Mg. Para Eucalyptus spp., observa-se a seguinte ordem: $\mathrm{Ca}>\mathrm{N}>\mathrm{K}>\mathrm{Mg}>\mathrm{P}$, e para o Pinus spp. $\mathrm{N}>\mathrm{K}>\mathrm{Ca}>\mathrm{Mg}>\mathrm{P}$.

Apesar de a quantidade de nutrientes exportados na casca, em termos quantitativos, ser inferior à do lenho, não se deve menosprezar a sua importância na nutrição e sustentabilidade florestal, uma vez que, devido à constituição física daquele componente, a decomposição e a liberação dos nutrientes são mais aceleradas que as do lenho.

Quanto à variação dos nutrientes exportados nas diferentes idades, é válida a mesma explicação dada ao componente lenho, ou seja, a exportação dos nutrientes, para a idade de oito anos, é cerca de $50 \%$ maior que para a idade de 12 anos. Isso se explica devido à maior quantidade de árvores, cerca de $50 \%$ da população inicial, que são desbastadas na idade de oito anos. A maior exportação de nutrientes aos 16 anos em relação aos 12 anos deve-se também ao maior volume atingido e, conseqüentemente, ao maior acréscimo do conteúdo de nutrientes nas árvores.

\section{CONCLUSÕES}

A utilização do estimador de biomassa SisPinus permite a estimativa dos nutrientes exportados para os diferentes regimes de manejo (desbastes e corte final), idades e produtividades, com pequenos ajustes, bastando apenas a inserção das equações previamente selecionadas no sistema SisPinus.

$\mathrm{O}$ ajuste das equações desenvolvidas para a população amostrada, dentro da variação de idade, qualidade do sítio, intensidade de manejo, entre outras variáveis, foi extremamente elevado, permitindo alta confiabilidade nas equações para estimativa de exportação dos nutrientes. 
Tabela 4. Exportação de nutrientes pela casca $(\mathrm{kg} / \mathrm{ha})$ com utilização das equações desenvolvidas e de posse do simulador SisPinus para $P$. taeda, em função da idade de desbaste $(8,12,16$ anos e corte final aos 20 anos).

Table 4. Nutrients exportation through the bark $(\mathrm{kg} / \mathrm{ha})$ with the use of development equations in SisPinus simulator for Pinus taeda, considering thinning age $(8,12,16$ and final harvest at 20 years).

\begin{tabular}{lcccccc}
\hline $\begin{array}{l}\text { Idade } \\
\text { (anos) }\end{array}$ & Situação & N & P & K & Ca & Mg \\
\hline 8 & Total & 15,5 & 1,9 & 11,0 & 8,9 & 3,2 \\
& Remanescente & 9,8 & 1,2 & 7,0 & 5,6 & 2,0 \\
& Removido & 5,7 & 0,7 & 4,0 & 3,3 & 1,2 \\
12 & Total & 25,4 & 2,9 & 10,6 & 15,7 & 5,2 \\
& Remanescente & 21,7 & 2,4 & 8,2 & 13,6 & 4,4 \\
& Removido & 3,7 & 0,5 & 2,4 & 2,1 & 0,8 \\
16 & Total & 39,7 & 4,2 & 10,7 & 26,3 & 8,0 \\
& Remanescente & 27,8 & 2,9 & 6,7 & 18,7 & 5,6 \\
& Removido & 11,9 & 1,3 & 4,0 & 7,6 & 2,4 \\
20 & Total & 36,7 & 3,8 & 7,6 & 25,2 & 7,3 \\
& Remanescente & 0 & 0 & 0 & 0 & 0 \\
& Removido & 36,7 & 3,8 & 7,6 & 25,2 & 7,3 \\
\hline Total & Removido & 58,0 & 6,3 & 18,0 & 38,2 & 11,7 \\
\hline
\end{tabular}

\section{AGRADECIMENTOS}

À Universidade Federal do Paraná, pela contribuição no aprimoramento científico, com o qual possibilitou a realização deste trabalho.

Às empresas Manasa (Madereira Nacional S.A.) e Santa Maria Papel e Celulose, pela cessão do material florestal e auxílio pessoal nas coletas das amostras em campo.

À EMBRAPA (Empresa Brasileira de Pesquisa Agropecuária), pelo apoio nas análises laboratoriais e cessão das instalações para preparação das amostras.

\section{REFERÊNCIAS}

ALEMDAG, I. S. Manual of data collection and processing for the development of forest biomass relationships. Petawawa: Petawawa National Forestry Institute, 1980. 38 p.

BALLONI, E. A.; JACOB, W. S.; SIMÕES, J. W. Resultados parciais de experimentação desenvolvida pelo setor de implantação florestal com diferentes espécies de Pinus. Boletim Informativo IPEF. Piracicaba, v. 6, n. 18, p. 1-117, jul. 1978.

CARVAlho, A. P. de; MENEGOL, O.; OliveIRA, E. B. de; MACHADO, S. A.; POTTER, R. O.; FASOLO, P. J.; FERREIRA, C. A., BARTOZESCK, A. Efeitos de características do solo sobre a capacidade produtiva de Pinus taeda. Boletim de Pesquisa Florestal, Colombo, n. 39, p. 51-66, jul,/dez. 1999.

CASTRO, C. F. de; POGGIANI, F.; NICOLIELO, N. Distribuição da fitomassa e nutrientes em talhões de Pinus oocarpa com diferentes idades. IPEF, Piracicaba, n. 20, p. 61-74, 1980.

CASTRO, C. F. de A. Distribuição da fitomassa acima do solo e nutrientes em talhões de Pinus oocarpa Schiede plantados no estado de São Paulo. Dissertação (Mestrado em Engenharia Florestal) Escola Superior de Agricultura Luiz de Queiroz, Universidade de São Paulo, Piracicaba, 1984.

COWN, D. J. Wood density of radiata pine: its variation and manipulation. New Zealand Jounal of Forestry Science, Rotorua, v. 19, p. 84-94, 1974. 
EMPRESA BRASILEIRA DE PESQUISA AGROPECUÁRIA (EMBRAPA). Carta de levantamento de reconhecimento dos solos do Paraná. Brasília, DF, 1984.

FERREIRA, C. A.; SILVA, H. D. da; REISSMANN, C. B.; BELlOTE, A. F. J.; MARQUES, R. Nutrição de Pinus no Sul do Brasil: diagnóstico e prioridades de pesquisa. Colombo: EMBRAPA Floresta. 2001. 23 p. (Documentos, n. 60).

DING, J. M. The influence of silvicultural practices on wood properties. International Review of Forestry Research, New York, v. 2, p. 95-126, 1967.

GONÇALVES, J. L. M. Recomendações de Adubação para Eucalyptus, Pinus e Espécies Típicas da Mata Atlântica. ESALQ/USP. Documentos Florestais, Piracicaba, n. 15, p. 1-23, 1995.

GONÇALVES, J. L. M.; MORO, L. Uso da "cinza" de biomassa florestal como fonte de nutrientes em povoamentos puros de Eucalyptus grandis. IPEF, Piracicaba, n. 48/49, p. 28-37, 1995.

HAAG, H. P. (Ed.). Nutrição mineral de Eucalyptus, Pinus, Araucaria e Gmelina no Brasil. Campinas: Fundação Cargill, 1983. 202 p.

JONHSON, R. A.; WIECHERN, D.W. Applied multivariate statistical analysis. New Jersey: Prentice Hall, 1998.

KOEHLER, C. W. Variação estacional da deposição da serapilheira e de nutrientes em povoamentos de Pinus taeda na região de Ponta Grossa - PR. 148 f. Tese (Doutorado em Engenharia Agronômica) Setor de Ciências Agrárias, Universidade Federal do Paraná, Curitiba, 1989.

LASO GARICOITS, L. S. Estado nutricional e fatores do solo limitantes do crescimento do $\boldsymbol{P}$. taeda L. em Telêmaco Borba PR. 128 f. Dissertação (Mestrado) - Setor de Ciências Agrárias, Universidade Federal do Paraná, Curitiba, 1990.

MÄLKÖNEM, E. Effect of whole-tree harvesting on soil fertility. Silva Fennica, Helsinki, v. 10, n. 3, p. 157-64, 1976.

MENEGOL, O. Índice de sítio e relação entre altura e teores nutricionais das acículas em povoamentos de Pinus elliottii var. elliottii no segundo planalto paranaense. 74 f. Dissertação (Mestrado em engenharia Florestal) - Setor de Ciências Agrárias, Universidade Federal do Paraná, Curitiba, 1991.

MORO, L.; GONÇALVES, J. L. M. Efeito da "cinza" de biomassa florestal sobre a produtividade de povoamentos puros de Eucalyptus grandis e avaliação financeira. IPEF, Piracicaba, n. 48/49, p. 18-27, 1995.

MORO, L. Exportação de Nutrientes em Povoamentos de Pinus taeda L. Baseada em Volume Estimado pelo Sistema Sispinus. 113 f. Tese (Doutorado em Engenharia Florestal) - Setor de Ciências Agrárias, Universidade Federal do Paraná, Curitiba, 2005.

NICHOLLS, J. W. P. The effect of environment on wood characteristics. Silvae Genetica, Frankfurt, v. 20, n. 3, p. 67-73, 1971.

OHTA, S. The observation of tree ring structure by soft x-ray densiometry (III). The influence of fertilization on ring structure of Pinus pinaster. Moduzai Gakaishi, [S.1.], v. 27, p. 157-162, 1981.

OLIVEIRA, E. B.; OLIVEIRA, Y. M. M. SisPinus - Desenvolvimento e Perspectivas. In: ENCONTRO BRASILEIRO DE ECONOMIA E PLANEJAMENTO FLORESTAL, 2., 1991 Curitiba. Anais... Curitiba: EMBRAPA/CNPF. 1992.

OLIVEIRA, E. B.; OLIVEIRA, Y. M. M.; HAFLEY, W. L. Um software para predição do crescimento e da produção de Pinus elliottii e $P$. taeda sob manejo no sul do Brasil. Pesquisa Agropecuária Brasileira, Notas científicas, Brasília, DF, v. 26, n. 1, p. 149-151, 1991.

OLIVEIRA, E. B.; PENTEADO, S. R. C.; OLIVEIRA, Y. M. M. ; IEDE, E. T. A Utilização do Software SisPinus no Planejamento da Produção de Povoamentos de Pinus elliottii Engel e Pinus taeda L. com 
Ataque de Sirex noctilio Fabricius, 1793 (Hymenoptera: Siricidae). In: CONFERÊNCIA REGIONAL DA VESPA DA MADEIRA, SIREX NOCTILIO, NA AMÉRICA DO SUL, 1992, Florianópolis. Anais... Colombo, EMBRAPA/CNPF, 1992. p. 161-167.

PINHEIRO, G. S. Estimativa do peso de copas de Pinus caribaea Morelet variedade hondurensis Barr. et Golf. e Pinus oocarpa Shiede, através de parâmetros dendrométricos. 105 f. Dissertação (Mestrado em Engenharia Florestal) - Setor de Ciências Agrárias, Universidade Federal do Paraná, Curitiba, 1980.

POGGIANI, F.; COUTO, H. T. Z. do; SUITER FILHO, W. Biomass and nutrient estimates in short rotation intensively cultured plantation of Eucalyptus grandis. IPEF, Piracicaba, n. 23, p. 37-42, 1983.

PRITCHETT, W. L.; ZWINDORF, K. R. Response of slash pine to colloidal phosphate fertilization. Soil Science of America Proceedings, Madison, v. 25, n. 5, p. 397-400, 1961.

REISSMANN, C. B.; WISNIESWSKI, C. Aspectos nutricionais de plantios de Pinus. In: GONÇALVES, J. L. M.; BENEDETTI, V. (Eds.). Nutrição e fertilização florestal. Piracicaba: IPEF, 2000. p. 135-166.

REISSMANN, C. B.; ZÖTTL, H. W. Problemas nutricionais em povoamentos de Pinus taeda em áreas do arenito da formação Rio Bonito-Grupo Guatá. Revista do Setor de Ciências Agrárias, Curitiba, n. 9, p. 75-80, 1987.

REISSMANN, C. B. Nährelement Versorgung und Wuchsleistung von Kiefernbeständen in Süd Brasilien. 169 f. Tese (Doktorwürde) - Albert-Ludwigs-Universitat. Forstwissenschaftlichen Fakultât, Freiburg, 1981.

REISSMANN, C. B.; KOOEHLER, C. W.; PAULA SOUZA, M. L. de. Classificação de sítio para Araucaria angustifolia, Pinus taeda e Pinus elliottii no $2^{\circ}$ Planalto do Paraná: Subprojeto I. Nutrição. [Curitiba]: UFPR / FUNPAR / FINEP, 1990. p. 1-286.

RIGATTO, P. A. Influência dos Atributos do Solo sobre a Produtividade e a Qualidade da Madeira de Pinus taeda para Produção de Celulose Kraft. 120 f. Dissertação (Mestrado em Agronomia) - Setor de Ciências Agrárias, Universidade Federal do Paraná, Curitiba, 2002.

ROYSTON, P. Approximating the Shapiro-Wilks W-Test for normality. Statistics and Computing. London, n. 2, p. 117-119, 1992.

RUDMAN, P.; MCKINNELL, F. H. Effect of fertilizers on wood density of young radiata pine. Australian Forest Research, Camberra, v. 34, p. 170-178, 1975.

SILVA, H. D. da. Modelos matemáticos para a estimativa da biomassa e do conteúdo de nutrientes em plantações de Eucalyptus grandis Hill (ex-Maiden) em diferentes idades. $101 \mathrm{f}$. Tese (Doutorado em Engenharia Florestal) - Setor de Ciências Agrárias, Universidade Federal do Paraná, Curitiba, 1996.

SILVA, H. D. da; BELlOTE, A. F. J.; DEDECEK, R. A.; GOMES, F. S. dos. Adubação mineral e seus efeitos na produção de biomassa em árvores de Pinus taeda L. In: CONGRESSO FLORESTAL BRASILEIRO, 8., 2003, São Paulo. Anais... São Paulo: Sociedade Brasileira de Silvicultura, 2003. 1 CD-ROM.

SINGH, T. Biomass equations for ten major tree species of the pairie provinces. Environment Canada. Canadian Forestry Service, Ottawa, n.2, 35 p, 1982.

SMITH, P.F. Mineral Analysis of plant tissue. Annual Review of Plant Physiology, Palo Alto. v. 13, p. 81-108, 1962.

SOCIEDADE BRASILEIRA DE SILVICULTURA. O Setor Florestal Brasileiro: fatos e números. São Paulo, 1998. 18 p.

TIMONI, J. L.; PAGANO, S. N. Caracterização e quantificação de elementos minerais de um povoamento de Pinus kesiya Royle ex Gordon no município de Itirapina (SP). Silvicultura, Rio de Janeiro, v. 11, n. 41, p. 69, 1986. 
TREVISAN, E. Classificação e caracterização de horizontes orgânicos sob povoamentos de Pinus taeda L, na região de Ponta Grossa - PR. $1^{\text {a }}$ aproximação. 111 f. Dissertação (Mestrado em Engenharia Florestal) - Setor de Ciências Agrárias, Universidade Federal do Paraná, Curitiba, 1992.

VALERI, S. V. Exportação de Biomassa e Nutrientes de Povoamentos de Pinus taeda L. Desbastados em Diferentes Idades. 164 f. Tese (Doutorado em Engenharia Florestal) - Setor de Ciências Agrárias, Universidade Federal do Paraná, Curitiba, 1988.

VAN LEAR, D. H. et al. Biomass and nutrient content of a 41-years-old loblolly pine (Pinus taeda L.) plantation on a poor site in South Carolina. Forest Science, Lawrence, v.30, n. 2, p. 395-404, 1984.

VOGEL, H. L. M. Crescimento de Pinus taeda L. relacionado a doses de N, P e K e sua diagnose nutricional pelo DRIS. Ciência Florestal, Santa Maria, v. 13, n. 1, p. 182, 2003.

WELLS, C. G.; JORGENSEN, J. R. Effect of intensive harvesting on nutrient supply and sustained productivity. In: IMPACT OF INTENSIVE HARVESTING ON FOREST NUTRIENT CYCLING, 1979, Syracuse, NY. Proceddings... New York: State University of New York, 1979. v. 6. p. 212-30. 